\title{
SMR2011-6596
}

\section{ITALY RE-OPENING THE NUCLEAR OPTION: ARE SMR A SUITABLE CHOICE? \\ AN APPLICATION OF THE INCAS MODEL}

\author{
Eng. Sara Boarin \\ Politecnico di Milano \\ Energy Department \\ Milan, Italy \\ saraboarin@gmail.com
}

Prof. Mauro Mancini Ph.D.

Department of Management, Economics \&

Industrial Engineering

Milan, Italy

Mauro.mancini@polimi.it

\author{
Eng. Giorgio Locatelli Ph.D. \\ Department of Management, Economics \& \\ Industrial Engineering \\ Milan, Italy \\ giorgio.locatelli@polim.it
}

\author{
Prof.Marco E. Ricotti Ph.D. \\ Politecnico di Milano \\ Energy Department \\ Milan, Italy \\ Marco.ricotti@polimi.it
}

\section{ABSTRACT}

The Italian strategic plan for the energy policy targets $25 \%$ of the national generation mix covered by nuclear technology by 2030 . Considering a demand for electric power of $340 \mathrm{TWh}$ in 2010 and assuming an annual rate of increase between 2,5\% and $1,0 \%$, the national plan would require to build some $8-10$ large nuclear power plants, at least. The new generation capacity may be covered by EPR or AP1000 technology or, alternatively, by multiple SMR (i.e. 300-150 MWe), or even a mix of LR and SMR.

The original intent, prior to the stop imposed by the dramatic earthquake and tsunami in Japan, was to have the first plant deployed by 2020. Today the Italian strategy to re-open the nuclear option is undergoing hard criticism and its fate is currently uncertain. In this context, this paper might contribute to the debate, by exploring the economics of the nuclear option with a focus on the opportunity to invest in large NPP category rather than in multiple, modular SMR. The latter have features that may compensate the dis-economy of scale and improve their cost-effectiveness, while granting investors with a lower up-front investment and a higher capability of project selffinancing. The analysis is run through the Polimi's proprietary "INtegrated model for the Competitiveness Analysis of Small modular reactors" (INCAS).Even if some specific inputs are related to the Italian scenario (e.g. the Electricity price) the results can be generalized to countries or utilities that are planning to install more than $10 \mathrm{GWe}$ of nuclear capacity.

\section{INTRODUCTION: ITALY AND NUCLEAR POWER}

\subsection{Electric power consumption and sources in Italy}

With limited domestic energy sources, and not commercial nuclear plants, Italy is highly dependent on energy imports. Italy has proven crude oil reserves of 0.7 billion barrels however, the domestic production of approximately 100000 barrels per day meets only a limited amount of domestic consumption. In the last decade, the declining production from Italy's natural gas fields and the increases in domestic consumption have increased the country's reliance upon gas imports which arrive mainly by pipelines. Natural gas, renewable sources and solid fuels are gradually replacing oil in electricity generation. Final energy consumption has been increasing, while industry remains the most energy-consuming sector. Energy intensity is below EU-27 average, while $\mathrm{CO} 2$ emission intensity is slightly above EU-27 average. [1]

The total consumption of EE in the 2010 has been 338,963 GWh, distributed as following [2]

- $\quad$ Not renewable $219,750 \mathrm{GWh} 64.8 \%$

- Renewable 75,269 GWh 22.2\%

- $\quad$ Net import 43,944 GWh $13.0 \%$ 
Natural gas alone accounts for $153,800 \mathrm{GWh}$, the $45.4 \%$ of the total consumption. $90 \%$ of this gas is imported from North Africa and Russia.

\subsection{Nuclear power in Italy}

Italy was a pioneer of civil nuclear power and in 1946 established the first scientific body to pursue this resource. In 1952, it established the National Committee for Nuclear Research (CNRN) to develop and promote nuclear power, and this was reorganized in 1960 to become the National Committee for Nuclear Energy (CNEN, now the ENEA) Construction of the first civil reactor - a British Magnox gascooled reactor - began in 1958 at Latina, and the following year construction of the first General Electric (GE) boiling water reactor (BWR) commenced at Garigliano. Construction of a Westinghouse pressurized water reactor (PWR) started in 1961 at Trino Vercellese, also known as the Enrico Fermi Nuclear Power Plant.

Anti-nuclear sentiment grew during the 1970s, although the nuclear industry continued to receive support from the national government. In the early 1980s, steps were taken to develop a standardized design. An energy plan adopted in October 1981 called for three new plants of 2x1000 MWe each at Piedmont (the Trino site), Lombardy and Puglia. The reference design of these reactors would be based on Westinghouse PWR technology and developed within the Unified Nuclear Project (Progetto Unificato Nucleare, PUN). Alongside this project, Enel continued with plans to build two 982 MWe BWR units at the Montalto di Castro site. Construction commenced in 1982, but the project was delayed as a result of local opposition.

A new energy plan was adopted by parliament in March 1986 one month before the accident at Chernobyl - that called for further increases in nuclear capacity. [3]

On 8 November 1987 the Italians were called to express their opinion on the possibility of stopping the civilian nuclear program. As Italy is close to Chernobyl, $80 \%$ of the votes were favorable to closing the program. Because of lack of funds and, generally speaking, mismanagement of the different governments in charge, the four nuclear plants existing in Italy were put on hold, but the decommissioning started only in 2003. [4]

\begin{tabular}{|c|c|c|c|c|c|}
\hline Reactor site & Type & $\begin{array}{c}\text { Net } \\
\text { MWe }\end{array}$ & $\begin{array}{c}\text { Contruction } \\
\text { Start }\end{array}$ & $\begin{array}{c}\text { First } \\
\text { power }\end{array}$ & Closedown \\
\hline Latina & Magnox & 153 & 1958 & 1963 & 1987 \\
\hline Garigliano & BWR & 150 & 1959 & 1964 & 1982 \\
\hline Trino Vercellese & PWR & 260 & 1961 & 1964 & 1990 \\
\hline Caorso & BWR & 860 & 1970 & 1978 & 1990 \\
\hline $\begin{array}{c}\text { Montalto di } \\
\text { Castro }\end{array}$ & BWR & $2 \times 982$ & 1982 & - & - \\
\hline
\end{tabular}

Table1 - Italian NPP

\subsection{Scenarios in the pre- Fukushima events}

In 2004, a new energy law opened up the possibility of joint ventures with foreign companies in nuclear power generation and allowed the electricity import from them.

After a memorandum of understanding in May 2005, Electricité de France (EDF) and Enel (the larger Italian Utility ${ }^{1}$ ) signed an agreement in November 2007 that gives Enel a 12.5\% share (some $200 \mathrm{MWe}$ ) in the Flamanville-3 EPR nuclear reactor project (1650 MWe), currently under construction in France, and an option for the same stake in the next five such units to be built. Enel is also to be involved in design, construction and operation of the plants, thereby helping to rebuild Italy's nuclear skills and competences. Expected investment in the construction of Enel's share of Flamanville-3 is approximately $€ 500$ million; Enel is also responsible for its pro quota share of operation costs. The agreement also gave EDF an option to participate in construction and operation of future Enel nuclear power plants in Italy or elsewhere in Europe and the Mediterranean. To this end, in August 2009, EDF and Enel set up a 50:50 joint venture company, Sviluppo Nucleare Italia (SNI), to conduct feasibility studies preliminary to the construction of at least four 1650 MWe Areva EPR units.

In May 2008, the Italian government confirmed its strong support to the nuclear program and declared that it would foster the construction of first new nuclear power plant within five years, to reduce the country's great dependence on oil, gas and imported power. The government introduced a package of nuclear legislation, including measures to set up a national nuclear research and development entity, to define criteria and procedures for reactor plants licensing and nuclear sites identification and licencing. The comprehensive economic development legislation was finally approved in July 2009 making nuclear power a key issue of the new energy policy, with a $25 \%$ target of electricity generation from nuclear power by 2030 . A national Nuclear Safety Agency has been set up in 2010.

In January 2011, the Constitutional Court ruled that Italy could hold a referendum on the planned re-introduction of nuclear power, as proposed by an opposition party. The question to be posed in the referendum, due to be held in mid-June, is whether

1 As well as its participation in new build in France, Enel is playing an active role in other countries. In 2004, it bought $66 \%$ of Slovakia's SlovenskeElectrarne (SE) with its four VVER 440/V213 Bohunice and Mochovce reactors there. Enel's subsequent investment plan included the completion of Mochovce units 3 \& 4 - 942 MWe gross - by 2011-12 (see section on New nuclear capacity in the information page on Nuclear Power in Slovakia).In February 2009, Enel bought 25\% of Spain's Endesa power producer for $€ 11$ billion, taking its ownership to $92 \%$. Endesa has equity in most of Spain's nuclear reactors: $100 \%$ of Ascó 1; $85 \%$ of Ascó 2; $72 \%$ of Vandellós 2; 36\% of the two Almaraz units; and 50\% of Garoñam.In April 2010, Enel signed a wide-ranging agreement with Russia's Inter RAO UES which positions it to take up to a 49\% share in Rosenergoatom's new 2340 MWe Baltic nuclear power plant being built in Kaliningrad. This will be the first Russian nuclear plant with private or international equity, and Inter RAO intends to export about two-thirds of the power to Germany, Poland and the Baltic states [4]. 
voters want to cancel some 70 legislative and regulatory measures which have been taken by the government over the last three years to allow new nuclear power plants deployment. Public hearing would not affect plans for a waste repository.

\subsection{Post - Fukushima event}

March 11 - Fukushima I nuclear accidents (further information in [5]). As an aftermath of this dramatic event, on the wave of a strong opposition of the public opinion to the nuclear renaissance, Italian government set a moratorium of the procedures for the national sites identification and of all the legislative activity necessary to the NPP realization. . [6] The moratorium resolution is in line with the general European debate for a deep reconsideration of the nuclear option and a reassessment of the safety issues, with more conservative criteria. The Italian Supreme Court will rule about the revocation of the public hearing about the nuclear option on account of the moratorium.

\section{THE INCAS MODEL}

Polimi's nuclear economics research group is developing the INCAS (INtegrated model for the Competitiveness Assessment of SMR) model as the founding theoric and simulation framework for the economic comparative assessment of investment projects in SMR versus large NPP .

INCAS is a unique model able to account for "economy of multiples" benefits that characterize SMR investment paradigm.

For the purpose of this analysis, INCAS consider about nominal 11,000MWe total capacity, installed either through multiple SMR or multiple LR. A comparative assessment of the alternative investment projects is performed, considering different plant size, configurations and technologies. INCAS' "Investment Model" relies upon a cash flow analysis over the plant lifetime, feeded by all the main input of an economic and financial analysis (revenues, operating and capital costs, financial costs). The output of the analysis is a complete set of indicators and values of financial performance: profitability for a private investor or economic soundness for a public stakeholder. Monetary factors are considered together with other strategic factors generally not easily quantifiable (e.g. social acceptability) that may be differential between different NPP projects and are able to influence the investment success. These are considered as external factors and evaluated in a dedicated model of INCAS. The approach is to assess the project attractiveness from a holistic point of view, The present analysis relies on the quantitative indicators provided by INCAS code.

The "Investment Model" is based on a Discounted Cash Flow model and provides the indicators of the investment's financial performances (e.g. IRR, NPV, cash flow profile). It includes the following modules:

- Generation costs (construction costs, operation and maintenance costs, fuel cycle, decontamination and decommissioning, amortization rate);

- Revenues;

- Financial (financing mix, cost of debt and equity, debt amortization period, tax rate, inflation, tax shield).

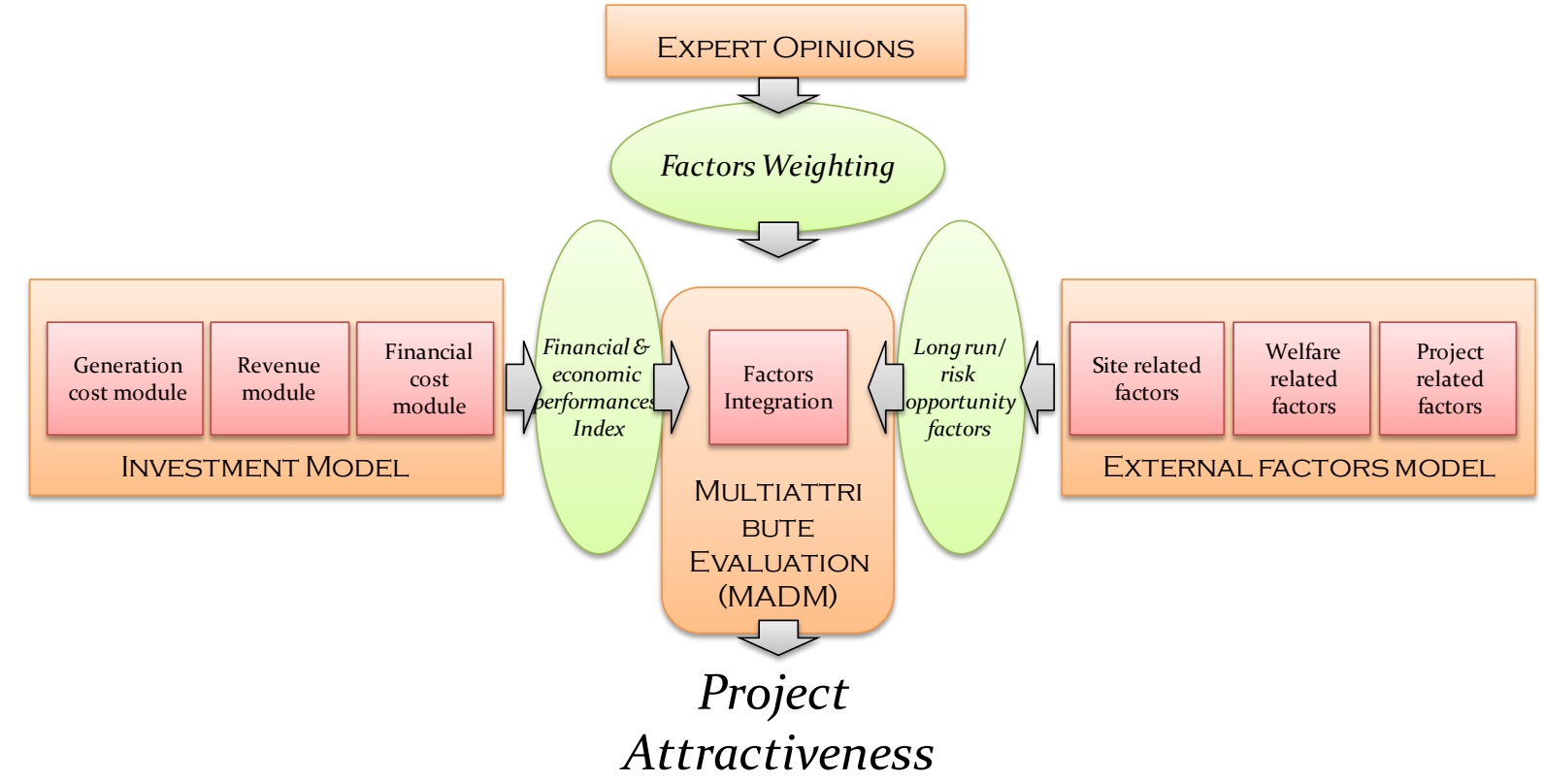

Figure 1 - The INCAS model 
Unlike other simulation codes, INCAS' Generation costs model is not a mere input section of the code: an original calculation routine allows to derive the construction costs of each successive NPP unit on the basis of its output size, design technology and learning accumulation. INCAS' premise is that the cost of " $n$ " NPP units is not equal to " $n$ " times the cost of one NPP. Starting from a reference construction cost for a given design technology and a given reactor size, INCAS is able to calculate the construction cost for each of the successive NPP units of the same design technology, through a top-down estimation approach and on the basis of a given construction strategy in terms of schedule and site location. In particular the code takes into account:

- economies of scale;

- co-siting economies, due to fixed costs sharing by NPP built and operated on the same site;

- construction cost savings, due to modularization effects, that are size-dependent;

- learning economies, both at single site level and worldwide, with two different learning accumulation and decay laws;

- effect of delay in the construction period;

- cost of financing during construction period.

\section{THE DESIGN ROBUSTNESS OF SMR}

A high level of safety is the result of a complex interaction between good design, operational safety and human performances, but design features are able to impact on all of these three dimensions. Design robustness encompasses three key strategic performance areas: reactor safety, radiation safety (public and occupational) and safeguards, according to Reactor Oversight Process (ROP) of NRC [7]. From these key areas, we define Design Robustness the reactor's capability to assure the core's integrity, the protection and the integrity of all the other components of the nuclear island, in order to guarantee the radiation safety of personnel, population and environment in every condition. A complete picture of SMR design and implication on the safety features is provided by [8].

Reactor safety considers accidents leading to significant, unmitigated releases from containment. Core Damage Frequency (CDF) and Large Early Release Frequency (LERF) are the most important indicators for this dimension. Lower plant size allows for higher degree of passive safety features and design simplification as respect to LR. Such enhancements drive to the elimination of several classical event initiators and guarantee higher efficiency of mitigating systems (i.e. natural convection of reactor coolant). As an example, advanced SMR have integrated primary circuit in the reactor vessel with the absence of large penetrations and pipes in and out the reactor vessel: this eliminates the LOCA accident type. Lower containment size allows for improved seismic isolation techniques, etc.. .As aresult example, safety-by-design approach of Westinghouse's IRIS permits a reduction of CDF from 5.1x10-7 of a GENIII+ AP1000 to 10-8 [9]. IRIS LERF is around five orders of magnitude less than large PWRs and the other GEN III+ SMR designs have a three orders lower one [10]. Occupational Radiation Safety refers to operators' overexposure risk. Plant workers can be exposed to a high-level radiation during the maintenance of reactor coolant pumps, pressurizers, water chambers of steam generators and during refueling. Operators exposure is then related to planned outages frequency for refueling and maintenance. SMR core is designed for extended life-cycle, reducing the frequency of operators activity in the nuclear island.

On the other side, outages are planned for each of multiple SMR units, considering the same installed power as LR.

Total exposure depends on overall number and duration of outages, on single outage exposure for operator and on number of operators involved in activities. If utilities follow best common practices during outages, occupational exposure will not penalize SMRs. Public Radiation Safety considers collective radiation exposure to liquid and gaseous effluents from routine nuclear reactor operations. Each SMR has lower source term as compared to a LR. This do not applies when we consider multiple the same total output at site level. On account of the higher safety performances estimated, studies have been done about the opportunity for the Regulator to reduce IRIS' EPZ to the boundaries of the plant. Safeguards refer to physical protection of the facility and proliferation resistance. Charlton [11] produces a report that can be considered the most relevant for this theme, synthesizing the parameter in a likelihood scale from 0 to 1 , where the highest is the value, the highest is the proliferation risk. For a typical PWR LR of GEN III this value is 0.07 , while for a SMR case with a batch loading of the fuel the parameter becomes 0.06 .

Moreover, portion of SMRs' containment can be located under the ground, as for IRIS, mPower: the cost would be prohibitive for LRs.This potential low SMRs' profile makes them an extremely difficult target for aircraft flying terrorists.

Design robustness is strictly design-specific but simplification, standardization and compactness of SMRs permit to obtain certain improvement on reactor safety and physical protection.

\section{INPUT AND SCENARIO DEFINITION}

For the purpose of this analysis we have assumed the specific cost input data from [5]. According to [5], we assumed as specific overnight construction cost the value of $3,137 € / \mathrm{kWe}$ installed for a reference 1,620 reactor plant. INCAS elaboration gives specific construction costs for each of the considered NPP sizes, accounting for the loss of EOS and the cost savings coming from modularization, site co-location, learning accumulation and design enhancements. The former are 
calculated on the basis of INCAS' built-in estimation models; the latter is derived from a much more conservative assumption than SMR vendors' declarations. Design saving factor represents cost savings from design-based enhancements and simplification as compared to same, advanced generation III large plants; this is the reason why we do not consider design cost saving factors for Very Large and Large Reactors.

SMR operating costs are derived from larger plants' value increased by a factor of $1.2 \mathrm{x}$, in consideration of a loss of EOS in operation and maintenance of multiple, smaller plants.

Considering the economics of NPP the main drivers are:

- Plants' size in terms of electric power output. It determines the Economy of scale application. Otherwise, INCAS assumes that the lower the size, the higher is the plant modularization and related construction cost savings.

- Construction strategy in terms of: site co-location of units, deployment time-schedule. These factors determine the degree of learning, co-siting economies and interest capitalization over the construction period.

Other country-specific input being equal (e.g. financial costs, EE price), four different plant sizes are considered in our scenarios $(1,600 \mathrm{MWe}, 1,200 \mathrm{MWe}, 300 \mathrm{MWe}$ and $150 \mathrm{MWe})$ to compare the opposite EOS and Economy of Multiples paradigms. Two scenarios are analyzed:

- a case where the NPP fleet is deployed by three utilities (a big player and two minor utilities);

- a case where the whole NPP fleet is deployed by a single, national investor-utility.

The comparison of these two scenarios allow to appreciate the effect of learning: in the three-investor scenario, the impact of learning is lower due to the lower number of NPP to be deployed. Plant modularization and design savings remain the same because they are size-dependent, while site-related fixed cost sharing is substantially unchanged because it depends on the number of NPP deployed on each site.

Fig. 2 and Fig. 3 present the siting configuration considering a total power of about nominal 11,000 MWe and five national nuclear sites operated by three utilities and by a single national player respectively.

In our scenario each site can host either one or two large plants $(1,600 \mathrm{MWe}$ or $1,200 \mathrm{MWe}$, "Very Large Reactor" and "Large Reactor" respectively) or a number of SMR (300MWe or $150 \mathrm{MWe}$ each; "Medium Reactor" and "Small Reactor" respectively) with equivalent total power.

\begin{tabular}{|l|l|l|c|c|}
\hline Acronym & VLR & LR & MR & SR \\
\hline Size [MWe] & 1,600 & 1,200 & 300 & 150 \\
\hline Life [y] & 60 & 60 & 60 & 60 \\
\hline Availability rate [\%] & 90 & 93 & 95 & 95 \\
\hline O\&M [€/MWh] [OECD] & 7.8 & 7.8 & 9.3 & 9.3 \\
\hline Fuel [€/MWh] [5] & 6.3 & 6.3 & 6.3 & 6.3 \\
\hline D\&D [€/MWh] [5] & 0.007 & 0.007 & 0.014 & 0.014 \\
\hline Design saving factor [\%] & na & na & 90 & 88 \\
\hline $\begin{array}{l}\text { Modularization saving } \\
\text { factor }{ }^{2}[\%]\end{array}$ & na & na & 85 & 73.7 \\
\hline Construction schedule [y] & $5-6$ & 5 & 3 & 3 \\
\hline
\end{tabular}

Table 2 - Reactor specific input

\begin{tabular}{|l|c|}
\hline Cost of Equity [Ke, \%] & 15 \\
\hline Financing Mix [E/(E+D), \%] & 50 \\
\hline Debt Amortization Period [y] & 15 \\
\hline Cost Of Debt [Kd, \%] & 8 \\
\hline Inflation [\%/y] & 1.9 \\
\hline EE Price [€/MWh] & 70 \\
\hline EE Increase [\%/y] & $2.1 \%$ \\
\hline Depreciation Fixed Assets [y] & 12.5 \\
\hline Tax Rate [\%] & $35 \%$ \\
\hline Risk Free Rate & $3 \%$ \\
\hline
\end{tabular}

Table 3 - Country specific input

\begin{tabular}{|c|c|c|c|c|c|c|c|}
\hline & site 1 & site 2 & site 3 & site 4 & site 5 & $\begin{array}{c}\text { total, } \\
\text { nominal } \\
\text { pwr [MWe] }\end{array}$ & $\begin{array}{c}\text { total, } \\
\text { effective } \\
\text { pwr } \\
{[\mathrm{MWe}]}\end{array}$ \\
\hline $\begin{array}{l}1600 \mathrm{MWe} \\
\text { num. of NPP }\end{array}$ & $\begin{array}{c}3200 \\
2\end{array}$ & $\begin{array}{c}3200 \\
2\end{array}$ & $\begin{array}{l}0 \\
0\end{array}$ & $\begin{array}{c}3200 \\
2\end{array}$ & $\begin{array}{c}1600 \\
1\end{array}$ & $\begin{array}{c}11200 \\
7\end{array}$ & $\begin{array}{c}10080 \\
7\end{array}$ \\
\hline 1200MWe & 2400 & 2400 & 1200 & 2400 & 2400 & 10800 & 10044 \\
\hline num. of NPP & 2 & 2 & 1 & 2 & 2 & 9 & 9 \\
\hline $\begin{array}{l}\text { 300MWe } \\
\text { num. of NPP }\end{array}$ & $\begin{array}{c}2400 \\
8\end{array}$ & $\begin{array}{c}2400 \\
8\end{array}$ & $\begin{array}{c}1500 \\
5\end{array}$ & $\begin{array}{c}1800 \\
6\end{array}$ & $\begin{array}{c}2400 \\
8\end{array}$ & $\begin{array}{c}10500 \\
35\end{array}$ & $\begin{array}{c}10500 \\
35\end{array}$ \\
\hline \multirow{2}{*}{$\begin{array}{l}\text { 150MWe } \\
\text { num. of NPP }\end{array}$} & 2100 & 1800 & 1800 & 2400 & 2400 & 10500 & 10500 \\
\hline & 14 & 12 & 12 & 16 & 16 & 70 & 70 \\
\hline
\end{tabular}

Figure 2 - Site collocation strategy of NPP: three utilities

\begin{tabular}{|c|c|c|c|c|c|c|c|}
\hline & & & & & & & \\
\hline & site 1 & site 2 & site 3 & site 4 & site 5 & $\begin{array}{c}\text { total, } \\
\text { nominal } \\
\text { pwr [MWe] }\end{array}$ & $\begin{array}{c}\text { total, } \\
\text { effective } \\
\text { pwr } \\
\text { [MWe] }\end{array}$ \\
\hline 1600MWe & 3200 & 3200 & 1600 & 1600 & 1600 & 11200 & 10080 \\
\hline num. of NPP & 2 & 2 & 1 & 1 & 1 & 7 & 7 \\
\hline 1200MWe & 2400 & 2400 & 2400 & 2400 & 1200 & 10800 & 10044 \\
\hline num. of NPP & 2 & 2 & 2 & 2 & 1 & 9 & 9 \\
\hline 300MWe & 2400 & 2400 & 2100 & 1800 & 1800 & 10500 & 10500 \\
\hline num. of NPP & 8 & 8 & 7 & 6 & 6 & 35 & 35 \\
\hline 150MWe & 2100 & 2100 & 2100 & 2100 & 2100 & 10500 & 10500 \\
\hline num. of NPP & 14 & 14 & 14 & 14 & 14 & 70 & 70 \\
\hline & & & UTILITY] & & & & \\
\hline
\end{tabular}

Figure 3 - Site collocation strategy of NPP: single utility

\footnotetext{
${ }^{2}$ INCAS elaboration
} 


\section{RESULTS}

Simulation results show SMR project capability to meet capital remuneration required (i.e.15\%; Tab.5). Given the uncertainty degree in the input and model assumptions, we may conclude that SMR cost effectiveness is in the range of Larger NPP: the impact of loss of EOS on project economics is recovered by Economy of Multiples paradigm and other design-specific features of SMR.

\begin{tabular}{|c|c|c|c|c|c|}
\hline & \multicolumn{2}{|c|}{ VLR } & LR & MR & SR \\
\hline SIZE [MWe] & \multicolumn{2}{|c|}{1,600} & 1,200 & 300 & 150 \\
\hline $\begin{array}{c}\text { Constr. } \\
\text { schedule [y] }\end{array}$ & 5 & 6 & 5 & 3 & 3 \\
\hline IRR [\%] & 14.3 & 13.9 & 14.0 & 15.0 & 15.2 \\
\hline $\begin{array}{c}\text { LUEC[€/M } \\
\text { Wh] }\end{array}$ & 75.3 & 79.0 & 77.0 & 72.6 & 70.2 \\
\hline
\end{tabular}

Table 4 - Three utilities scenario: profitability and cost efficiency indicators

These effects allow to contain specific overnight costs: due to the loss of EOS, overnight cost of first stand alone MR or SR (300MWe and 150MWe respectively) would be $89 \%$ and $146 \%$ higher than a single 1,600MWe NPP. Cost abatement due to economy of replication reduce the gap in unit overnight costs at $13 \%$ and $16 \%$ respectively (Fig.5). The much higher loss of EOS of SR is recovered by a high degree of modularization factor related to such a small scale (Fig.4).

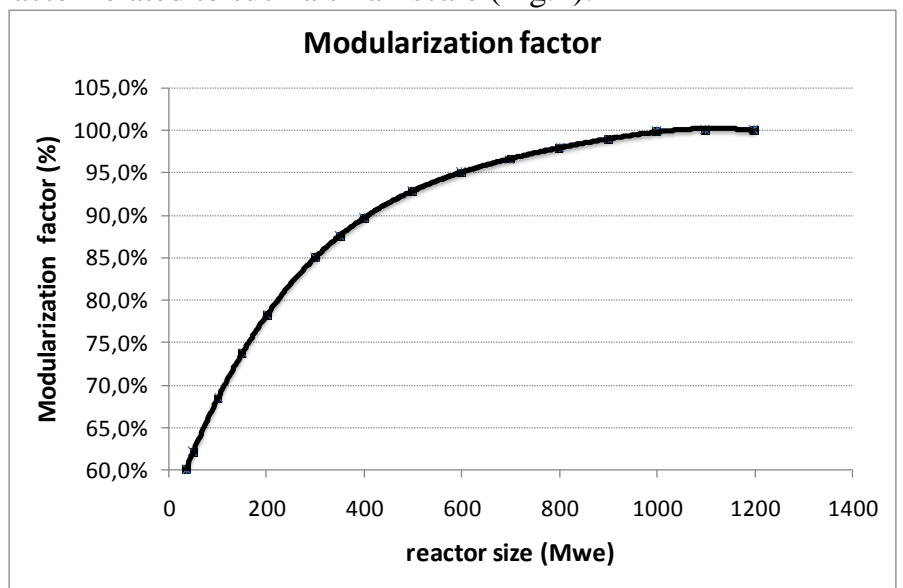

Figure 4 - Modularization saving factor

Discontinuities in TCIC per NPP are evident in Figure 9 where it progressively decrease all along with successive NPP, until a site change: learning on assembling and construction can only be partially transferred to other nuclear sites and therefore unit overnight construction costs of the first unit built on a new site is higher than the previous NPP built on the previous site.

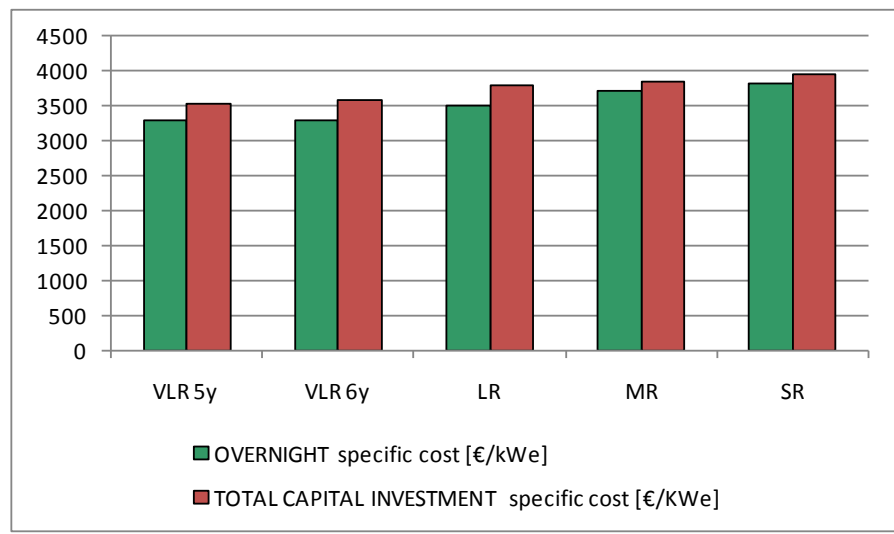

Figure 5 - Overnight and TCIC specific costs

Furthermore, when interest expenses are considered, the gap between SMR and larger NPP is reduced even more. Interest expenses are the cost of financial debt due to the lenders and they are capitalized during construction period, when the plant is not operating and earning any revenues from the electricity generation. Interest expenses during this period are called "Interest During Construction" and are added to the outstanding financial debt in order to generate further interest expenses on themselves. So, the more long-lasting is the construction schedule, the higher will be the effect of IDC capitalization. SMR have shorter construction periods and therefore shorter Pay Back Time on each NPP investment. The overall effect is a better control over interest capitalization and a limited TCIC. The latter is the sum of the overnight costs and IDC; SMR can compensate higher overnight costs with lower interest costs during construction (Tab.5) in order to have TCIC almost in line with larger plants. The gap is reduced to 7-10\% for SMR as compared to 1,600MWe plant (Fig.5). Better control on financial expenses is confirmed by total amount of interest expenses due during the whole project lifetime (Tab.5).

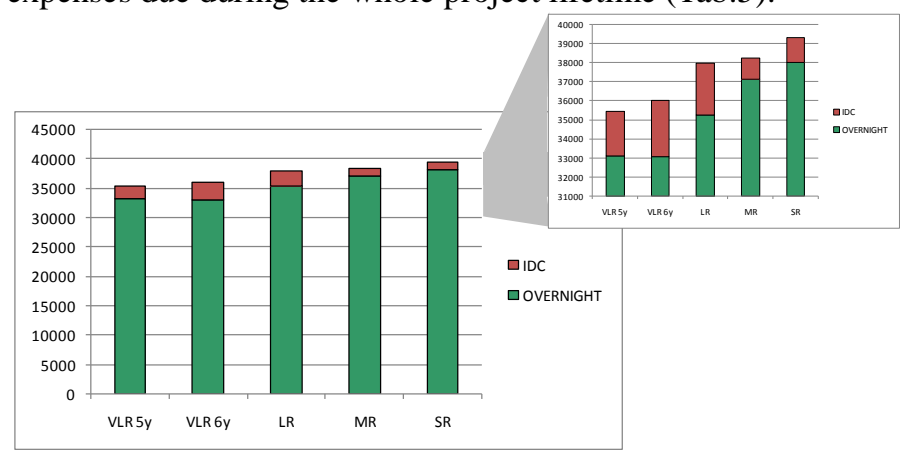

Figure 6-TCIC components: overnight costs and IDC

TCIC are break down in the three possible sources of financing: Equity, Debt and Self-financing; the latter represents an internal source of financing only when multiple, staggered NPP units are built. It represents the cash flow to the equity that is generated from the operation of the first units and is left after payment of debt obligations: it may be re-invested by shareholders in the project it-self, to finance the construction of later deployed units (Fig.9 and Fig.12). This investment source 
also requires a capital remuneration and has therefore a cost which is the cost of equity. Nevertheless it reduces the amount of the up-front investment by shareholders, making multiple NPP projects a more affordable project, with gradual capital investment effort and lower average capital at risk during the construction period.

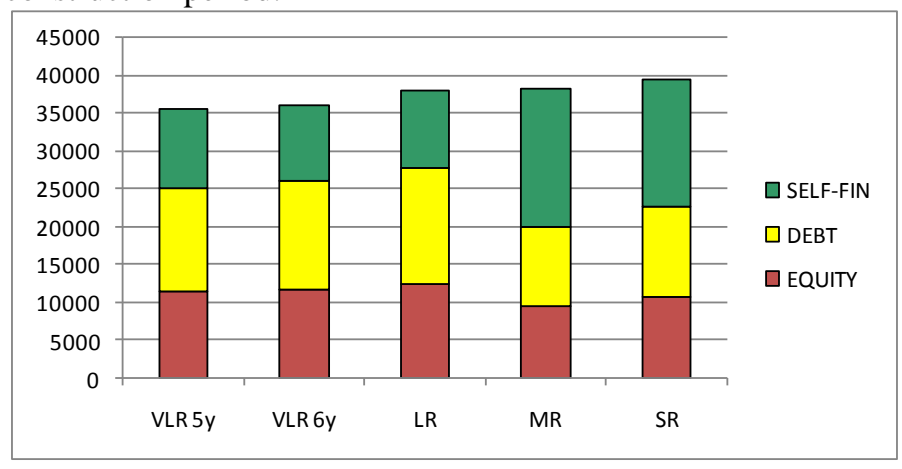

Figure 7 - Sources of financing

In our scenario, the sum of equity and debt up-front investment is significantly lower than for Large or Very Large Reactors (Fig.7). The balance is self-financed: capital is generated and invested all along the project. Cash-poorer investors may be able to deploy the same total power capacity with incremental investment in SMR, than bigger utilities do by mean of 1,600MWe units. SMR allow for a lower up-front investment effort and lower capital exposure during construction period on account of shorter PBT for each NPP. Cost of capital is negotiated between investors and lenders on the basis of the risk/remuneration expectations: lower up-front capital requirement means lower exposure risk by the investor/lender portfolio side and lower negotiated cost of capital, all other parameters being equal. This effect may account for lower cost of debt with a virtuous impact on SMR economics, but is not taken into account in this work. Outstanding financial debt evolution confirms this hint (Fig.14 and Fig.15). Cumulated cash flow curve of SMR project (Fig.10) shows shorter Pay Back Time and lower maximum negative cash outlay than LR and VRL (Fig.13 and Tab.5). The latter may be assumed as a measure of the financial distress of the project. An investment project with tight financial conditions is less robust to unfavorable scenario changes and this again concern investment risk considerations, which is as a relevant issue as is project profitability.

\begin{tabular}{|c|c|c|c|c|c|}
\hline & \multicolumn{2}{|c|}{ VLR } & LR & MR & SR \\
\hline Constr. Schedule [y] & 5 & 6 & 5 & 3 & 3 \\
\hline $\begin{array}{c}\text { Total financial } \\
\text { expenses [bn€] }\end{array}$ & 9.6 & 11.5 & 10.7 & 6.8 & 7.7 \\
\hline of which: & 2.3 & 2.9 & 2.7 & 1.1 & 1.3 \\
\hline IDC & -4.4 & -4.5 & -4.8 & -2.7 & -2.8 \\
\hline $\begin{array}{c}\text { Maximum cash } \\
\text { outlay UTILITY1 }\end{array}$ & -1.8 &
\end{tabular}

Table 5 - Results: financial distress

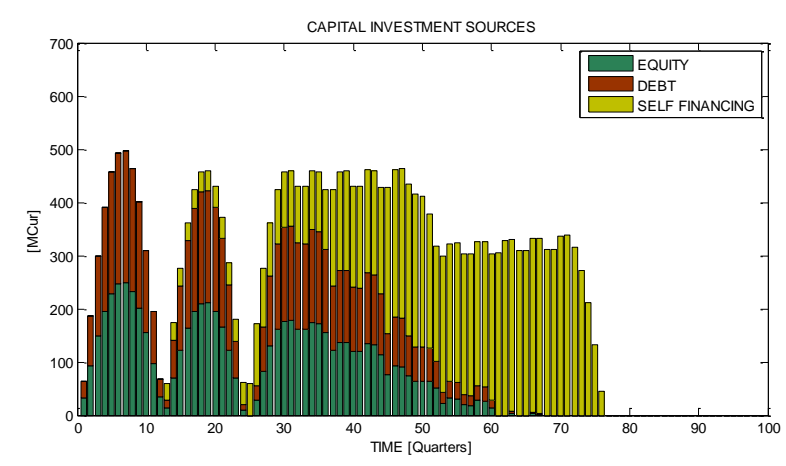

Figure 8 - Medium Reactors - UTILITY1: sources of financing per time-unit (quarter) during the construction period

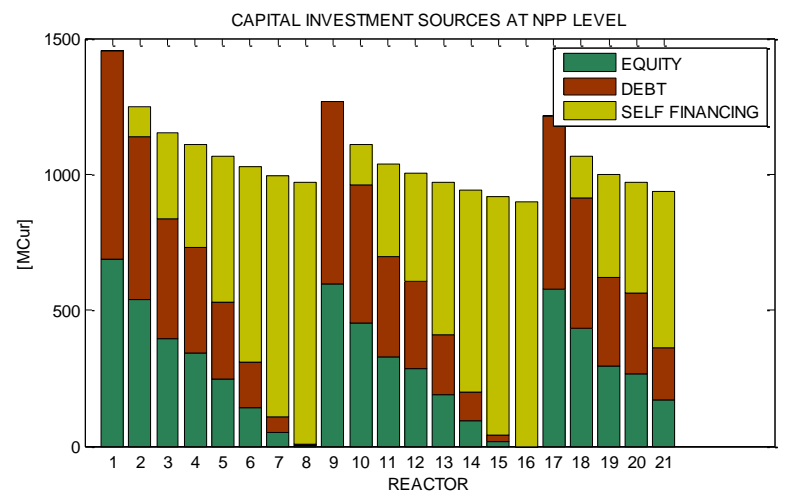

Figure 9 - Medium Reactors - UTILITY1: sources of financing per NPP

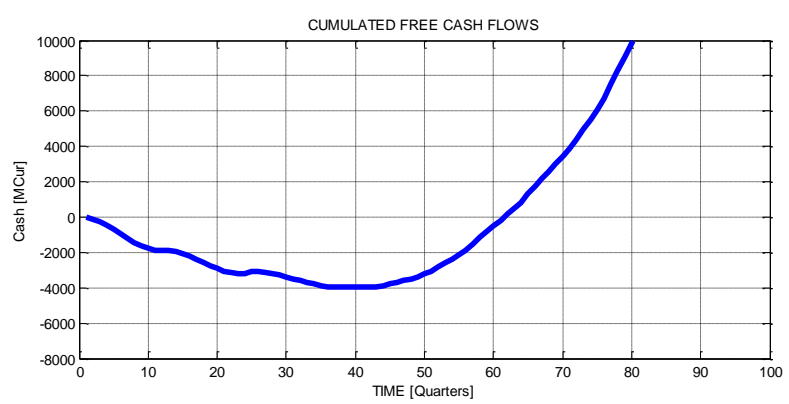

Figure 10 - Medium Reactors - UTILITY1: cumulated cash flow curve during the construction period

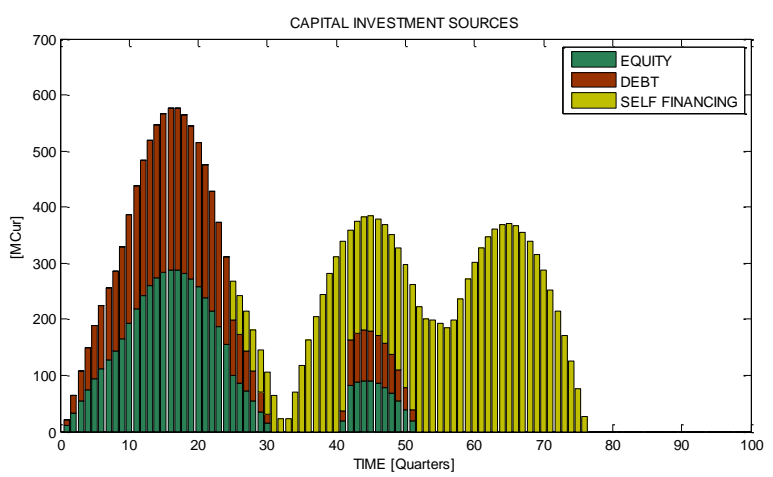

Figure 11 - Very Large Reactors - UTILITY1: sources of financing per time-unit (quarter) during construction period 


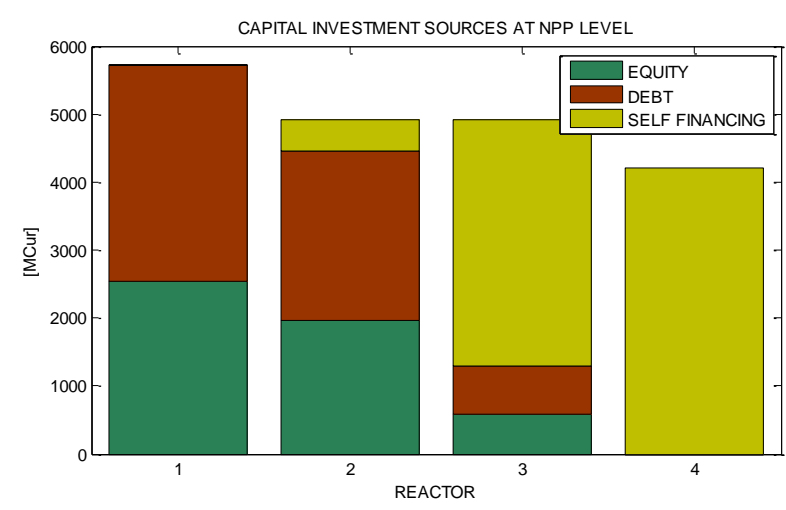

Figure 12 - Very Large Reactors - UTILITY1: sources of financing per NPP

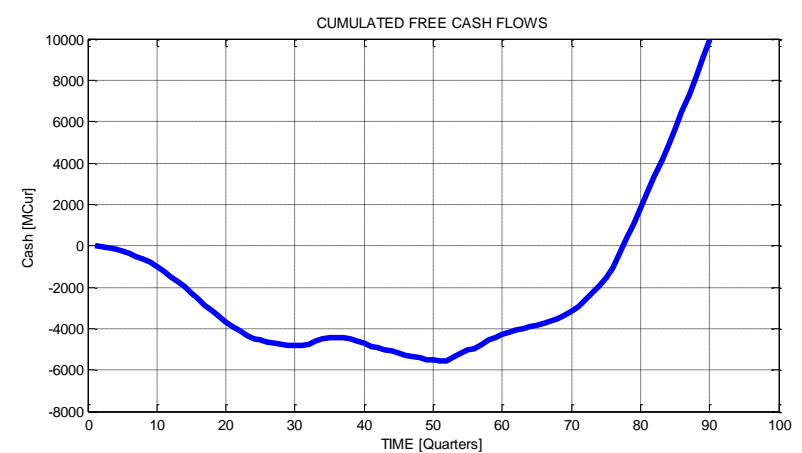

Figure 13 - Very Large Reactors - UTILITY1: cumulated cash flow curve during the construction period

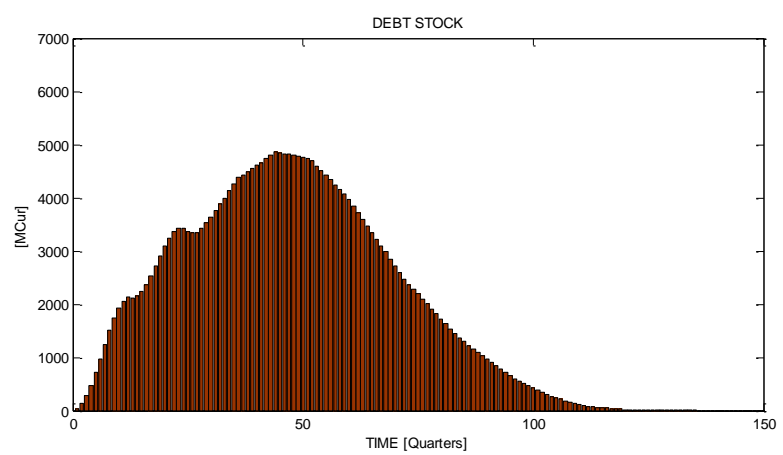

Figure 14 - Medium Reactors - UTILITY1: Debt stock

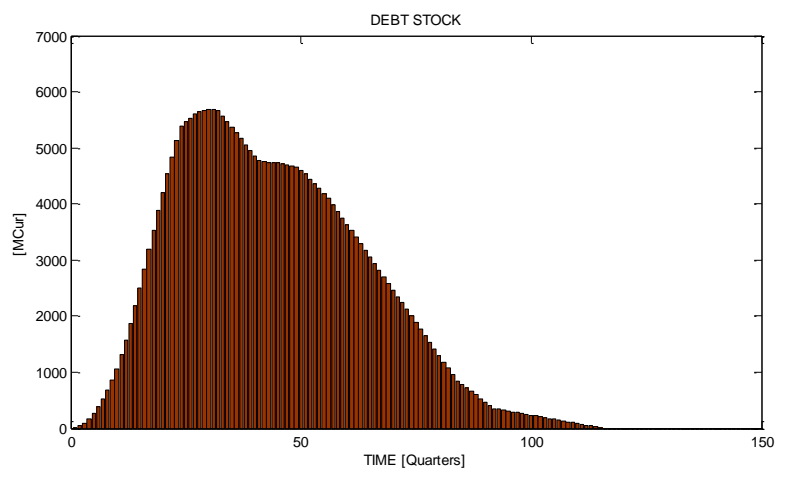

Figure 15 - Very Large Reactors - UTILITY1: Debt stock

When total nuclear capacity is considered as a whole investment project, smaller sized NPP exploit their full potential in terms of "Economy of Multiple" benefits (Tab.6), such as learning efficiencies and site-related fixed costs sharing.

Nevertheless multi-investor case is more realistic and represents the central reference case of this work.

\begin{tabular}{|c|c|c|c|c|c|}
\hline & \multicolumn{2}{|c|}{ VLR } & LR & MR & SR \\
\hline SIZE [MWe] & \multicolumn{2}{|c|}{1,600} & 1,200 & 300 & 150 \\
\hline $\begin{array}{c}\text { Constr. } \\
\text { schedule [y] }\end{array}$ & 5 & 6 & 5 & 3 & 3 \\
\hline IRR [\%] & 15.6 & 15.0 & 15.3 & 17.4 & 17.4 \\
\hline $\begin{array}{c}\text { LUEC[€/M } \\
\text { Wh] }\end{array}$ & 67.8 & 70.7 & 69.3 & 61.8 & 62.0 \\
\hline
\end{tabular}

Table 6 - Single utility scenario: profitability and cost efficiency indicators

\section{CONCLUSIONS}

The most severe criticism to the Italian nuclear program are project economics and safety.

As far as plants' safety is concerned, public acceptance should be differential toward a design technology with enhanced passive safety features allowed by the smaller reactor size. SMR's improved safety standard and lower CDF as respect to Large passive safety reactor concepts is due to more active component elimination, integration of primary circuit in the RV with LOCA elimination, natural convection of core coolant in accident events; higher seismic robustness is due to smaller size of containment and consequent more effective insulation techniques.

SMR's great challenge is the recovery of EOS as compared to large sized plants. Given our assumptions and specific scenario conditions, this analysis shows that Economy of Multiples, together with design simplification and modularization, account for the competitiveness of a batch of SMR as compared to larger NPP.

Investment modularization allowed by SMR, allows for cash transfer from early deployed units to later build ones with virtuous financial benefits: lower up-front investment, lower capital at risk during construction and lower financial distress of the project. This improves the project economics and reduces the investment risk.

For potential investors, SMR represent a scalable, flexible investment strategy for gradual new capacity installed, that give the option to increase, defer or even stop the investment process in case of very adverse conditions such as withdraw of political support. Shorter construction time and consequent shorter PBT for each SMR unit explains better IDC control over construction period, against considerable interest capitalization and TCIC escalation incurred by large plants' projects. 
SMR's LUEC may be some in line with current electricity cost in Italy. It has to be considered that generation costs from fossil-fuelled technologies will increase in the future on account of the carbon tax. Nuclear technology is neutral against carbon tax and its competitiveness against other technologies would enhance. SMR's LUEC is also in line with larger NPP, in the range of uncertainty that characterizes input parameters and models. SMR are then fully entitled to compete with large NPP and traditional carbon emitting technologies on their same marketplace.

\section{NOMENCLATURE}

$$
\begin{aligned}
& E=\text { Equity } \\
& D=\text { Debt } \\
& E E=\text { Electricity } \\
& E O S=\text { Economy of Scale } \\
& I D C=\text { Interests During Construction } \\
& I R R=\text { Internal Rate of Return }[\%] \\
& K_{e}=\text { cost of equity }[\% / y] \\
& K_{d}=\text { cost of debt }[\% / y
\end{aligned}
$$$$
\text { INCAS = Integrated model for the Competitiveness Analysis of }
$$$$
\text { Small-modular reactors }
$$$$
L O C A=\text { Loss Of Coolant Accident }
$$$$
L R=\text { Large Reactors [1,200MWe] }
$$$$
L U E C=\text { Levelized Unitary Electricity Cost [€/MWh] }
$$$$
M R=\text { Medium Reactors [300MWe] }
$$$$
N P P=\text { Nuclear Power Plant }
$$$$
N P V=\text { Net Present Value }
$$$$
O C C=\text { Overnight Construction Cost }
$$$$
P B T=\text { Pay Back Time [y] }
$$$$
R V=\text { Reactor Vessel }
$$

$S M R=$ Small Medium sized Reactors or Small Modular Reactors

$S R=$ Small Reactors [150MWe]

$T C I C=$ Total Capital Investment Cost

$V L R=$ Very Large Reactors [1,600MWe]

\section{REFERENCES}

1. European Commission website. ITALY - Energy Mix Fact Sheet. [Online] http://ec.europa.eu/energy/energy_policy/doc/factsheets/mix/mi x_it_en.pdf.

2. TERNA. Dati statistici sull'energia elettrica in Italia. Quadro di sintesi al 11 marzo 2011. 2011.

3. World Nuclear Association. Nuclear Power in Italy. [Online] $\quad 032011 . \quad$ http://www.worldnuclear.org/info/inf101.html.

4. The possible role of nuclear energy in Italy. Esposto, Stefano. 5, s.l. : Elsevier, 2008, Energy Policy, Vol. 36, p. 1584-1588.

5. IAEA. Fukushima Nuclear Accident. [Online] 15052010. http://www.iaea.org/.

6. World Nuclear News. Italy announces nuclear moratorium . [Online] 2403 2011. http://www.world-nuclear-news.org/NPItaly_announces_nuclear_moratorium-2403117.html.

7. Commission, U.S. Nuclear Regulatory. "Reactor Oversight Process", NUREG-1649. U.S. NRC. Washington D.C., United States : s.n., 2000.

8. IAEA. Design features to achieve defence in depth in small and medium sized reactors. 2009. IAEA Nuclear Energy Series - No. NP-T-2.2.

9. "The design and safety features of the IRIS reactor". Carelli, M.D., Conway, L.E., Oriani, L., Petrovic, B., Lombardi, C.V., Ricotti, M.E., Barroso, A.C.O., Collado, J.M., Cinotti, L., Todreas, N.E., Grgic, D., Moraes, M.M., Boroughs, R.D., Ninotaka, H., Ingersoll, D.T., Oriolo, F. 2004, Nuclear Engineering and Design, Vol. 230, p. 151-167.

10. "IRIS simplified LERF model". Maioli, A., Finnicum, D.J., Kumagai, Y. Miami, Florida, United States : s.n., 2004. ANES 2004 Proceedings of International Conference October 2004.

11. Charlton, W.S., Le Bouf, R.F., Gariazzo, C., Ford, D.G., Beard, C., Landsberger, S., Whitaker, M. "Proliferation resistence assessment methodology for nuclear fuel cycle". Nuclear Engineering Department, Texas A\&M University. Texas, United States : s.n., 2008. 
ANNEX A

CONSTRUCTION SCHEDULE
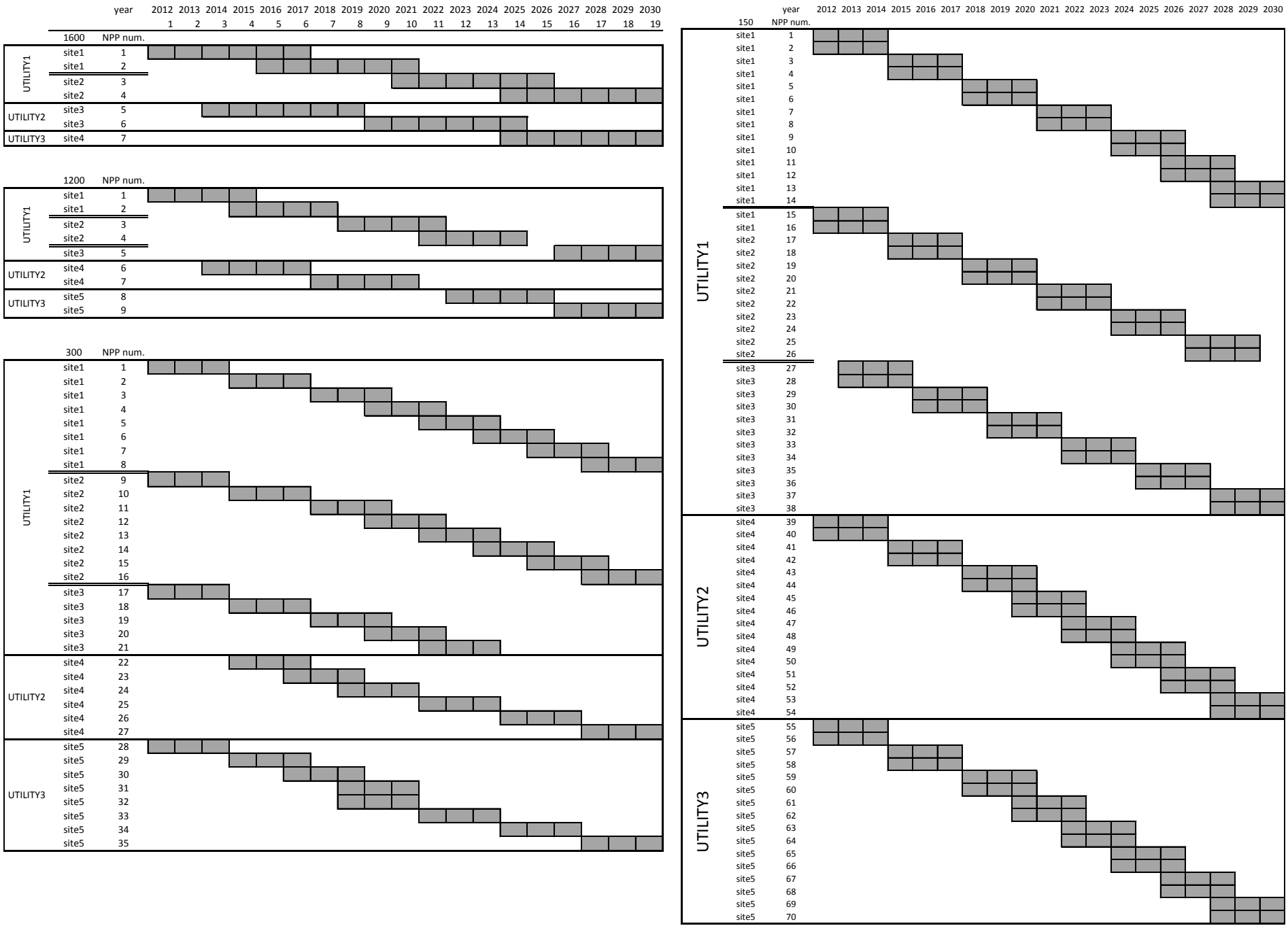